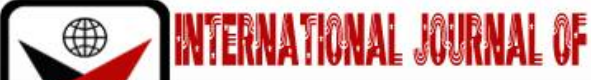

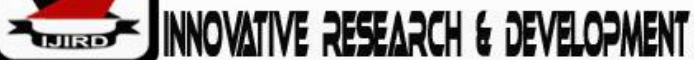

ISSN 2278-0211 (Online)

\section{Child Caregiver Knowledge on Infant and Young Child Nutrition in Urban and Rural Turbo Sub County, Uasin Gishu, Kenya}

\begin{tabular}{c}
\hline Nancy Imali Mdoga \\
Postgraduate Student, Department of Human Nutrition and Dietetics, \\
Kabarak University, Kenya \\
Pamela Kimeto \\
Wesley Bor \\
Wecturer, Department of Nursing, College of Health Sciences, Kabarak University, Kenya \\
Head, Department of Human Nutrition and Dietetics, Kabarak University, Kenya \\
\hline
\end{tabular}

\begin{abstract}
:
Background: Globally stunting affects about one fifth of children less than five years with more than a third from Africa. It is said to occur in children when their linear growth (length/height) in relation to age is lower than minus two standard deviation. Its occurrence has been seen to be the first 1000 days of life from conception to 23 months of age resulting in poor brain, organ and bone development. Stunted children have high morbidity, mortality rates. Long term effects include reduced individual output and predisposition to chronic conditions.

Objectives: The aim of this study was to establish child caregiver's knowledge on infant and young child nutrition for children less than two years in Turbo, Uasin Gishu County.

Method: Cross-sectional survey design was used for this study and two wards in Turbo Sub County were randomly selected. A sample size of 331 stunted children aged 0-23 months were recruited using multistage, systematic random sampling. The data was analysed using SPSS for windows version 20.

Results: Most of the children at 92.1\% were cared for by their biological mothers. Most caregivers listed breastmilk as the only food for children below 6 months at 80.9\%, urban and 78.4\%, rural though exclusive breastfeeding rates were at $40.3 \%$. There was good knowledge on timely initiation of breastfeeding at $85.6 \%$ and for urban and $75 \%$ for rural care givers. Rural caregivers had better knowledge on timely introduction of complimentary foods than urban caregivers with $\chi^{2}(P<0.001)$. Eggs was listed least as food for children 6-23 months at 3.7\% urban and $4.3 \%$ rural. Caregivers had poor knowledge on meal frequency with a significant difference between rural and urban at $\chi^{2}(P=0.033)$ and $\chi^{2}(P=0.019)$ for 9-11 and 12-23 months respectively.

Conclusion: The study indicate caregivers are aware on how to feed children less than six months than children 6-23 months. The study thus recommends training of health workers and community health volunteers on infant and young child nutrition to enable them reach caregivers at both health facility and community level.
\end{abstract}

Keywords: Nutrition, infant, children, knowledge

\section{Introduction}

Child poor nutrition status is a global challenge that has been addressed over years to reverse negative trends and its effect on growth and development. In 2015 child nutrition was given a new focus through the Sustainable Development Goal 2 that need to be achieved by 2030 of ending hunger, achieve food security, good nutrition and promoting agriculture, (Prendergast \& Humphrey, 2017). Stunting in children was estimated at $22.2 \%$ globally in 2017 being a reduction from $32.6 \%$ in 2000. Stunting in Africa was estimated at 39\%. Though this reduction indicates effectiveness of interventions employed, these achievements were not seen in some continents as Asia and Africa. Asia reduced stunting from $38.1 \%$ in 2000 to $23.2 \%$ in 2017 while in Africa it reduced from 38.3\% to 30.3\% during the same period. Eastern Africa had highest stunting rates at $35.6 \%$ while North Africa was lowest at $17.3 \%$ in 2017, (WHO, 2018).

Demographic health surveys conducted in East African countries in three consecutive years indicated that Tanzania had the highest stunting rates at 34.5\% in 2015, Uganda at 28.9\% in 2016 while Kenya was lowest at 26.2\% in 2014, (UNICEF, 2019) Stunting levels were reported highest in West Pokot and Kitui counties which had $45.9 \%$ and $45.8 \%$ respectively. Uasin Gishu county was at 31.2\%, (KDHS, 2014). The stunted children's future health, well-being and individual output is adversely affected. Under nutrition is recognized as one of the largest contributors to negative outcomes in relation to the growth and developments of countries. This is due to the challenge it poses to the health of people and productivity of populations (Sorgho et al., 2016). The health risks include high morbidity and mortality owing to poor immunity in 
stunted children resulting from low fat mass, (Briend et al., 2015\&Yaméogo et al., 2017). Stunting also results in obesity, with higher prevalence's of diabetes, hypertension and cardiac diseases in adults of short stature, and reduced intellectual performance due to poor brain cell development, (Hassen et al., 2017\&Prendergast et al., 2017).

In 2015 countries were given a challenge to work towards ending all forms of malnutrition including stunting by $40 \%$ by 2025. These efforts are geared towards achieving the Sustainable Development Goals (SDGs) 2 and 3 that focuses on hunger, status of food security, nutrition ,agriculture, healthy lives and wellbeing for all ages, (IFPRI, 2016). Stunting has also been included as one of the indicators for measuring hunger globally and food insecurity, giving it a special focus in interventions, (Global Hunger Index, 2015). Out of 7293 children assessed nationally 1597 (21.9\%) had a HAZ score of less than minus 2 . The proportion of children stunted increased with age where only $10 \%$ of children less than 6 months were stunted and $35.5 \%$ for 18 to 23 months indicating a problem with child care as age progresses, (KDHS, 2014). Efforts have therefore been put in place by the international community, NGO's and governments towards improving nutrition status of children. This includes addressing the four pillars of food security that comprise food availability, consistency in the supply of food, easy food access and proper utilization of the ingested food by the body, (FAO, 2009).

Comparing Uasin Gishu stunting rates (31.2\%) to other food producing counties like Nandi $29.9 \%$ and Trans Nzoia 29.2\%, the findings indicate other factors other than household food security could be contributing to stunting in children in agricultural rich zones, (CFSVA, 2016). This is not true for all agricultural rich counties in Kenya with Nyeri County which is a food secure having lowest stunting rates of $15.1 \%$. Turkana which is relatively drier had a stunting rate of $23.9 \%$ which was lower than some food producing regions, (KDHS, 2014). Therefore, there seems to be a major research gap to contributors of stunting in some counties that have shown to be food secure with acceptable at household access of food level in Kenya more so in Turbo Sub County, Uasin Gishu County. Studies are required to establish these factors to ensure informed interventions at County and national level.

\subsection{Statement of the Problem}

Optimal growth in children is achieved by the foods they consume besides other factors that include environmental, social economic, cultural or individual differences, (Herforth \& Ahmed, 2015). When children receive sufficient nutrients, they grow among other body measures in their height, weight with a strong immunity, (Njiru \& Matiri, 2013). However, when this is not met, stunting occurs in children where they do not achieve their required height for age. Despite a report that households in Uasin Gishu had better food access with acceptable food consumption score (FCS) and an average house hold dietary diversity score (HDDS) of 6.7, it recorded wasting prevalence of $3 \%$ which is acceptable, but stunting was in the 'serious stage', a prevalence of 31.2\% for children under five, (Leroy et al., 2015 \& CFSVA, 2016).This indicates that about a third of the children are at risk of the negative effects of stunting.

Since the effects of stunting are permanent and response to intervention is been found to be more effective in the first 1000 days of life, Ghosh, (2016) \&Prendergast et al., (2017), prevention of stunting should be given priority. This will help reduce its negative effects of stunting and ensure healthy productive individuals. This study therefore, determines the possible contributors to stunting for children less than two years in Turbo Sub County, Uasin Gishu County.

\subsection{Purpose of Study}

The intent of this study was to examine caregiver knowledge on infant and young child feeding practices as contributing factor to stunting in children less than two years in Turbo Sub County of Uasin Gishu County.

\subsection{Research Questions}

Do caregivers of children less than two years in Turbo, Uasin Gishu County have appropriate knowledge on infant and young child nutrition practices?

\subsection{Significance of the Study}

In this study we focused on finding contributors to stunting so as to inform focus areas in prevention programs. This was important since prevention mitigates the negative effects of stunting. Recommendations from this study will inform interventions on feeding practices of communities at household level. Communities will be advised on how to identify contributors to stunting and take preventive measures in time. Key persons concerned with child nutrition both at community level will undergo capacity building on implementation of community programs designed to address stunting in children. Finally, this study aimed at forming a basis for the ministry of health, ministry of education, the county government and stakeholders in establishing informed intervention programs and provides a guide to evaluation of any programs already addressing stunting in the county to see whether they are addressing the actual causes as studied.

\section{Methodology}

\subsection{Research Design}

Cross sectional survey design was employed in this study as Kothari, (2004) argues that descriptive survey can be used where study participants can be interviewed directly or indirectly and results obtained can reflect practices of the entire population. In this study caregivers of stunted children will be surveyed in Turbo Sub County

\subsection{Research Setting}

The study was carried out in Huruma and Ng'enyilel wards in Turbo sub county, Uasin Gishu County. It is located west of Eldoret town along Eldoret Malaba highway. These locations were randomly sampled. Huruma and Nge'nyilel were 
selected to represent the urban and rural area respectively. The study was conducted in households selected from villages randomly sampled from the community units.

\subsection{Research Study Population}

The target population for this study was children less than two years who live in Turbo Sub County, Uasin Gishu County. This population of study was selected since studies have shown stunting occurs within this age group and reversal is possible if interventions are done before children reach two years of age.

\subsection{Sample Size Determination}

The sample size was drawn from the target population of children under two years. Turbo had a total population of 272,985 persons in 2018 from the last census report. Based on the population's proportions, children under five are $15.5 \%$ of the total population resulting to 42,313, (KNBS, Census, 2010). Assuming uniformity in the population distribution for the following ages in months, $(0-11,12-23,24-35,36-47,48-59)$ then $2 / 5$ of the population was children less than 23 months, is 16,925 .

Turbo Sub County has six administrative wards with the population distributed proportionally as follows; Huruma ward (18.7\%), Kamagut ward (21.8\%), Kapsaos ward (13.6\%), Kiplombe ward (12\%), Ngenyilel ward (9.9\%), and Tapsagoi ward (24\%).

Children below 2 years of age calculated in proportion to the population were 3,164 from Huruma ward and 1676 from Ngenyilel ward. The sampling frame was 4,840 children less than two years.

The sample size was calculated using the formula by Fisher et al., (1991).

$\mathrm{nf}=\mathrm{n} /(1+(\mathrm{n}) / \mathrm{N})$, when the population is less than 10,000 .

$\mathrm{z}=\quad$ the standard normal deviation, level of significance 0.05 .

$\mathrm{CI}=\quad$ 1-0.05 giving $95 \%$ confidence level which is set at 1.96 .

$\mathrm{p}=\quad$ the proportion of the target population estimated to have a particular characteristic of stunting. The documented prevalence rates are $31.2 \%$ (0.312), (KDHS 2014).

$\mathrm{q}=\quad$ the proportion of the population estimated not to have the characteristics of stunting (1.0-0.312), 0.688.

$\mathrm{d}=\quad$ the degree of accuracy required which is set at 0.05 corresponding to the 1.96

$\mathrm{n}=\quad \frac{1.96^{2} \times 0.312(1-0.312)}{0.0529}$ children

$\mathrm{nf}=\quad 329 /(1+\underline{329})=329 / 1.068$

4840

$\mathrm{nf}=308+10 / 100$ of 308

Sample size $=331$ children

Therefore Huruma ward $65 \%$ of $331=215$ children were studied

Ngenyilel ward $35 \%$ of $331=116$ children were studied

\subsection{Sampling Technique}

A Multi stage systematic random sampling one ward was randomly chosen from two urban wards and one ward from wards from the four rural wards. The urban wards are Huruma and Kapsaos from which Huruma ward was randomly selected. Kamagut, Kiplombe, Ngenyilel and Tapsagoi wards are in the rural areas and Ngenyilel ward was randomly selected to represent rural households.

Community units were selected randomly from Huruma and Ng'enyilel wards. Villages were then selected randomly from the community units from which households to be interviewed were randomly drawn.

\subsection{Instrumentation}

This study employed the use of a researcher administered questionnaire. A standard-length board was used to measure length of children.

\subsection{Pre-Testing of Study}

This was carried out in Kapsaos ward which has both rural and urban settlements. The sample size for pretesting was 10, (Chaudhary \& Israel, 2014). The results from the pretesting were used to revise questions, add explanations and clarified questions and the process to the data collectors.

\subsection{Research Instrument}

\subsubsection{Validity}

The researcher ensured validity by using a measuring length board with clear markings. Content validity was made sure by asking questions that answered each objective exhaustively, (Kothari, 2004).

\subsubsection{Reliability}

To increase reliability, research assistants were trained together to reduce interviewer error, and use of clear questions that generate one answer when used across respondents. Using SPSS 2020 test retest reliability of the researcher administered questionnaire was computed giving a Cronbach value of 0.892 . 


\subsection{Data Collection Method}

Data was collected by asking questions to the respondents and filling in researcher administered questionnaires. Data collectors included a qualified nutritionist licenced by the Kenya Nutritionist and Dietetics Institute and a Community Health Volunteers who are attached to the community unit and are familiar with households visited.

The length of children was measured using the following procedure with use of length board.

- The child's caregiver lays the child on their back on the length board and assists the nutritionist by holding the child's head in place.

- The caregiver soothes the baby to help him/her calm down

- The caregiver was shown to firmly hold the child's head against the fixed head board as she continues to reassure the child.

- The nutritionist ensures the child lies straight with shoulders touching the board and the spine not arched.

- The nutritionist then holds the child's legs with one hand applying gentle pressure to avoid injuring the child and the other hand moves the footboard to straightened toes.

- The measurement was the read in centimetres to the nearest $0.1 \mathrm{~cm}$

Stunting was the determined by using the WHO height for age growth charts 2006, (WHO Growth Standards 2006). Children who had LAZ of less than -2 were classified as moderate stunting while those with less than -3 were classified as severe stunting.

Foods consumed by children were determined using a 24-hour recall by asking caregivers to recall the types of food fed to children the previous day and night.

\subsection{Data Analysis}

The researcher counted and grouped data collected. IBM SPSS version 20 was used to analyse data. Measures of central tendency were used to get a representative figure of different variables. Frequencies were calculated for categorical variables. Cut off points for WHZ score were at <-2 for moderate stunting and <-3 for severe stunting. Dietary diversity scores were determined by counting number of food groups consumed. The strength of association between variables was calculated using Pearson chi square and fishers' exact test. Bar graphs and tables were used for displaying analysed data.

\subsection{Ethical Consideration}

The researcher sought permission from the Kabarak University Ethics Research Committee and National Commission for Science, Technology and Innovation before proceeding to collect data. Permission from the ministry of health Uasin Gishu County was also given for this study. Consent was sought for both the caretakers and the child. Participation was voluntary and those who wished to opt out while the study is on were allowed to do so. Participants were not coerced or threatened to participate the research and they were informed there was no compensation for participating in the study. It was explained to the participants that confidentiality will be ensured and this was done by giving each participant a code and individual names were not used. The researcher remained sensitive to the participants concerns through the study.

\section{Results}

\subsection{Demographic and Socio-Economic Status for Participants}

\begin{tabular}{|c|c|c|c|c|}
\hline & & $\begin{array}{c}\text { Urban } \\
n=215 \\
n(\%)\end{array}$ & $\begin{array}{c}\text { Rural } \\
n=116 \\
n(\%)\end{array}$ & $\begin{array}{c}\text { Total } \\
\mathrm{n}=331 \\
\mathrm{n}(\%)\end{array}$ \\
\hline \multirow[t]{2}{*}{ Stunted child distribution } & Moderate stunting & $139(64.7)$ & $79(68.1)$ & $218(65.9)$ \\
\hline & Severe stunting & $76(35.3)$ & $37(31.9)$ & $113(34.1)$ \\
\hline \multirow[t]{4}{*}{ Child's age group } & $0-<6$ & $34(15.8)$ & $28(24.1)$ & $62(18.7)$ \\
\hline & $6-11$ & $60(27.9)$ & $22(19.0)$ & $82(24.8)$ \\
\hline & $12-17$ & $55(25.6)$ & $31(26.7)$ & $86(26.0)$ \\
\hline & $18-23$ & $66(30.7)$ & $35(30.2)$ & $101(30.5)$ \\
\hline \multirow[t]{2}{*}{ Childs sex } & Males & $96(44.7)$ & $52(44.8)$ & $148(44.7)$ \\
\hline & Female & $119(55.3)$ & $64(35.0)$ & 183(55.3) \\
\hline \multirow{4}{*}{$\begin{array}{l}\text { Caregivers relationship } \\
\text { to child }\end{array}$} & Mother (female parent) & 199(92.6) & $106(91.4)$ & $305(92.1)$ \\
\hline & Father (male parent) & $4(1.9)$ & $5(5.3)$ & $9(2.7)$ \\
\hline & Grandmother & $5(2.3)$ & $3(2.6)$ & $8(2.4)$ \\
\hline & Other & $7(3.3)$ & $2(1.7)$ & $9(2.7)$ \\
\hline \multirow[t]{4}{*}{ Caregivers education } & No formal education & $1(0.5)$ & $6(5.2)$ & $7(2.1)$ \\
\hline & Primary & $84(39.1)$ & $71(61.2)$ & $155(46.8)$ \\
\hline & Secondary & $104(48.4)$ & $33(28.4)$ & $137(41.4)$ \\
\hline & College & $26(12.1)$ & $6(5.2)$ & $32(9.7)$ \\
\hline
\end{tabular}

Table 1 


\subsection{Caregiver Knowledge on Infant and Young Child Feeding}

Caregiver's knowledge on feeding children was analysed for children 0-23 months. Knowledge aspects analysed included caregivers understanding on types of foods to be consumed by children less than 6 months and children 6-23 months, age at which a child is introduced to other foods, frequency of feeding children of different ages and quantity of foods for different age groups. Food measurements determining quantity were estimated against a standard measure of a 250-millilitre cup.

\subsubsection{Caregivers Knowledge on Feeding Children less than 6 months}

\begin{tabular}{|c|c|c|c|c|c|}
\hline \multirow{2}{*}{\multicolumn{2}{|c|}{$\begin{array}{c}\text { Knowledge } \\
\text { area }\end{array}$}} & \multirow{2}{*}{$\begin{array}{c}\text { Urban } \\
\begin{array}{c}n=215 \\
\text { n (\%) }\end{array}\end{array}$} & \multirow{2}{*}{$\begin{array}{c}\text { Rural } \\
\text { n=116 } \\
\text { n(\%) }\end{array}$} & \multicolumn{2}{|c|}{ Chi Square Results } \\
\hline & & & & & P value \\
\hline \multirow{3}{*}{$\begin{array}{l}\text { Timely Initiation of breast } \\
\text { feeding }\end{array}$} & Within 1 hour & $184(85.6)$ & $87(75.0)$ & \multirow{3}{*}{5.692} & \multirow{3}{*}{0.058} \\
\hline & Till milk comes & $20(9.3)$ & $19(16.4)$ & & \\
\hline & Don't know & $11(5.1)$ & $10(8.6)$ & & \\
\hline \multirow{3}{*}{$\begin{array}{l}\text { Foods for children 0-5 } \\
\text { Months }\end{array}$} & Breast milk only & $174(80.9)$ & $91(78.4)$ & \multirow{3}{*}{3.460} & \multirow{3}{*}{0.177} \\
\hline & $\begin{array}{l}\text { Breast milk and } \\
\text { semi solid foods }\end{array}$ & $30(14.0)$ & $13(11.2)$ & & \\
\hline & Don't know & $11(5.1)$ & $12(10.3)$ & & \\
\hline \multirow{4}{*}{$\begin{array}{l}\text { Introduction of } \\
\text { complimentary } \\
\text { Foods }\end{array}$} & At 6 months & $95(44.2)$ & $85(73.3)$ & \multirow{4}{*}{38.469} & \multirow{4}{*}{$0.000^{*}$} \\
\hline & 0-5 months & $42(19.5)$ & $12(10.3)$ & & \\
\hline & $>6$ months & $68(31.6)$ & $8(6.9)$ & & \\
\hline & Don't know & $4.7)$ & $11(9.5)$ & & \\
\hline
\end{tabular}

*Significant Value

Results on caregiver's knowledge on types of foods for children below 6 months and initiation of breastfeeding indicated no difference in understanding what food to feed this age group (breast milk) and when to initiate breastfeeding (within one hour after birth). There was a significant difference on understanding the right age to introduce foods between urban and rural residence.

\subsubsection{Feeding for Children Less Than 6 Months}

\begin{tabular}{|c|c|c|c|c|c|c|}
\hline Residence & $\begin{array}{c}\text { Age } \\
\text { 0-<6 } \\
\end{array}$ & \multicolumn{4}{|c|}{ Breastfeeding Type } & Total \\
\cline { 3 - 6 } & Months & $\begin{array}{c}\text { Exclusive } \\
\text { Breastfeeding }\end{array}$ & $\begin{array}{c}\text { Predominant } \\
\text { Breastfeeding }\end{array}$ & $\begin{array}{c}\text { Mixed } \\
\text { Feeding }\end{array}$ & $\begin{array}{c}\text { Not } \\
\text { Breastfeeding }\end{array}$ & \\
\hline & $(\mathrm{n})$ & $\mathrm{n}(\%)$ & $\mathrm{n}(\%)$ & $\mathrm{n}(\%)$ & $\mathrm{n}(\%)$ & $\mathrm{N}$ \\
\hline Urban & $(34)$ & $13(38.2)$ & $6(17.6)$ & $14(41.2)$ & $1(2.9)$ & 34 \\
\hline Rural & $(28)$ & $12(42.9)$ & $2(7.1)$ & $13(46.4)$ & $1(3.6)$ & 28 \\
\hline Total & $(62)$ & $25(40.3)$ & $8(12.9)$ & $27(43.5)$ & $2(3.2)$ & 62 \\
\hline
\end{tabular}

Table 3

Results foods consumed by children 0-6 months indicate that children exclusively breastfed were $40.3 \%$. Mixed feeding was the most practiced mode of feeding at $43.5 \%$ for both urban and rural respondents. Exclusive breastfeeding rates were higher at $42.9 \%$ in the rural and $38.2 \%$ in the urban area. More children in urban areas received liquids and water in addition to breast milk as predominant breastfeeding was at $17 \%$ compared to rural areas at $7.1 \%$.

\subsubsection{Caretaker's Knowledge on Frequency of Feeding children 6-23 months}

\begin{tabular}{|c|c|c|c|c|c|c|}
\hline $\begin{array}{l}\text { Age in } \\
\text { Months }\end{array}$ & $\begin{array}{c}\text { Knowledge on } \\
\text { Minimum Acceptable } \\
\text { Frequency } \\
\end{array}$ & $\begin{array}{l}\text { Urban } \\
n=215\end{array}$ & $\begin{array}{c}\text { Rural } \\
n=116\end{array}$ & Total & $\begin{array}{c}\text { Chi Square } \\
\text { Value }\end{array}$ & $\begin{array}{c}\text { Chi Square } \\
P=0.05\end{array}$ \\
\hline \multirow{2}{*}{$6-8$} & Yes & $71(33.0)$ & $38(32.8)$ & $109(32.9)$ & \multirow[t]{2}{*}{0.044} & \multirow[t]{2}{*}{0.835} \\
\hline & No & $144(67.0)$ & $78(67.2)$ & $222(67.1)$ & & \\
\hline \multirow{2}{*}{$9-11$} & Yes & $64(29.8)$ & $48(41.4)$ & $112(33.8)$ & \multirow[t]{2}{*}{4.358} & \multirow[t]{2}{*}{$0.033^{*}$} \\
\hline & No & $151(70.2)$ & $68(58.6)$ & $219(66.2)$ & & \\
\hline \multirow{2}{*}{$12-23$} & Yes & $55(25.6)$ & $44(37.9)$ & $99(29.9)$ & \multirow[t]{2}{*}{5.482} & \multirow[t]{2}{*}{ 0.019* } \\
\hline & No & $160(74.4)$ & $72(62.1)$ & $232(70.1)$ & & \\
\hline
\end{tabular}


Minimum acceptable frequency is the number of times children from different age groups are expected to consume food in a day. Children 6-8 months (2 times), 9-23 (3 times) and 6-23 months non-breastfed children (4 times), Source: Indicators for assessing IYCF, WHO 2008.

Results on caretakers understanding on frequency of feeding children, indicated most caretakers did not know the minimum acceptable frequency for feeding children from different age groups. There was a significant difference in understanding the minimum number of times to feed a child 9-11months $\left(\chi^{2} 4.358, p=0.033\right)$ and $12-23$ months $\left(\chi^{2} 5.432\right.$, $\mathrm{p}=0.019$ ) between rural and urban caregivers. Rural caregiver's having a better understanding than urban caregivers

\subsubsection{Knowledge on Food Groups for Feeding Children 6-23 months}

\begin{tabular}{|c|c|c|c|c|c|c|}
\hline \multirow[b]{2}{*}{ Food Groups } & \multicolumn{2}{|c|}{$\begin{array}{l}\text { Urban } \\
n=215\end{array}$} & \multicolumn{2}{|c|}{$\begin{array}{c}\text { Rural } \\
n=116\end{array}$} & \multirow[b]{2}{*}{$\begin{array}{c}\text { Chi Square } \\
\text { Value }\end{array}$} & \multirow[b]{2}{*}{$\begin{array}{l}\text { P value } \\
P=0.05\end{array}$} \\
\hline & $\begin{array}{c}\text { Yes } \\
\text { n(\%) }\end{array}$ & $\begin{array}{c}\text { No } \\
\text { n(\%) }\end{array}$ & $\begin{array}{c}\text { Yes } \\
\text { n(\%) }\end{array}$ & $\begin{array}{c}\text { No } \\
\text { n }(\%)\end{array}$ & & \\
\hline Flesh foods & $114(53.0)$ & $101(47.0)$ & $52(44.8)$ & $64(55.2)$ & 2.024 & 0.155 \\
\hline Legumes, nuts & $14467.0)$ & $71(33.0)$ & $84(72.4)$ & $32(27.6)$ & 1.039 & 0.308 \\
\hline Milks & $165(76.7)$ & $50(23.3)$ & $93(80.2)$ & $23(19.8)$ & 0.515 & 0.473 \\
\hline Fruits & 193(89.8) & $22(10.2)$ & $99(85.3)$ & $17(14.7)$ & 1.418 & 0.234 \\
\hline Vegetables & 192(89.3) & $23(10.7)$ & $84(72.4)$ & $32(27.6)$ & 15.511 & 0.000* \\
\hline Carbohydrates & 208(96.7) & $7(3.3)$ & 111(95.7) & $5(4.3)$ & 0.240 & 0.624 \\
\hline Eggs & $8(3.7)$ & $207(96.3)$ & $5(4.3)$ & 111(95.7) & 0.069 & 0.793 \\
\hline
\end{tabular}

*Significance Value

Caregivers understanding on food groups to be fed to children for both rural and urban had energy rich foods scoring highest. Eggs had the least score. There was no significant difference between urban and rural understanding of food groups to be fed to children except for vegetables, $\left(\chi^{2} 15.511, p<0.001\right)$, with more urban caregivers listing vegetables as one of the foods that should be fed to children than rural caregivers.

\subsubsection{Individual Food groups Consumed by Children 6-23 months}

\begin{tabular}{|c|c|c|c|c|}
\hline Individual Food Groups & Response & $\begin{array}{c}\text { Urban } \\
\mathbf{N}=181 \\
\mathbf{n}(\%)\end{array}$ & $\begin{array}{l}\text { Rural } \\
N=88 \\
n(\%)\end{array}$ & $\begin{array}{c}\text { Chi Square } \\
P=0.05\end{array}$ \\
\hline \multirow[t]{2}{*}{ Cereals, roots, tubers } & Yes & $176(97.2)$ & $83(94.3)$ & 0.338 \\
\hline & No & $5(2.8)$ & $5(5.7)$ & \\
\hline \multirow[t]{2}{*}{ Legumes, nuts } & Yes & $31(17.1)$ & $19(21.6)$ & 0.282 \\
\hline & No & $150(82.9)$ & $69(78.4)$ & \\
\hline \multirow[t]{2}{*}{ Milks and milk products } & Yes & $102(56.4)$ & $54(61.4)$ & 0.725 \\
\hline & No & $79(43.6)$ & $34(38.6)$ & \\
\hline \multirow[t]{2}{*}{ Flesh foods } & Yes & $40(22.1)$ & $15(17.0)$ & 0.481 \\
\hline & No & 141(77.9) & $73(83.0)$ & \\
\hline \multirow[t]{2}{*}{ Eggs } & Yes & $13(7.2)$ & $11(12.5)$ & 0.250 \\
\hline & No & $168(92.8)$ & $77(87.5)$ & \\
\hline \multirow[t]{2}{*}{ Vitamin A rich foods } & Yes & $26(14.4)$ & $31(35.2)$ & 0.001* \\
\hline & No & $155(85.6)$ & $57(64.8)$ & \\
\hline \multirow[t]{2}{*}{ Fruits and vegetables } & Yes & $126(69.6)$ & $64(72.7)$ & 0.862 \\
\hline & No & $55(30.4)$ & $24(27.3)$ & \\
\hline
\end{tabular}

Cereal, roots and tubers foods were eaten most in urban at $97.2 \% / n=196$ and rural 94.3\%/n=83. Eggs were eaten least with $7.2 \%$ urban and $12.5 \%$ rural. There were no differences in consumption of all food groups between urban and rural children except intake of vitamin A rich foods with a significant difference $\chi^{2}(\mathrm{p}=0.001)$. Vitamin A rich foods were eaten more in the rural areas compared to urban areas at $14.4 \%$.

\section{Discussion}

The study findings out that caregiver's had a better understanding on when to initiate breastfeeding which is recommended to be within one hour after birth unless the mother unable to breastfeed ,the child is orphaned unable to breastfeed due to various reasons, (MOH Nutrition Division, 2013 \&MIYCN Guidelines, 2012). Urban caregivers demonstrated a better understanding on what age to introduce complimentary foods to children than the rural caregivers. Since mixed feeding was practiced in this study, it implies that caregivers did not put in practice the knowledge on type of food for children less than six months. Although most respondents correctly identified breast milk as the only food for 
children below six months and the age for starting complimentary foods to children to be at six months, exclusive breastfeeding rates were low for children less than six months. According to Fairbrother \& Stanger-Ross, (2009), insufficient production of milk has been given as the most common reason for introducing foods before the age of six months. They further observed that lack of clear understanding of benefits of exclusive breastfeeding led to mixed feeding and stoppage of breastfeeding before children attained the age of two years.

Besides giving the right food for age, optimal nutrient intake for different age groups can only be achieved with intake of enough food. This is achieved when the caregivers adhere to the correct frequency of feeding and provision of the right quantity of food for the different age groups. Therefore, caregiver's knowledge on feeding frequency and quantity of feeds is paramount to child growth. In this study most caregivers did not know minimum acceptable number of times for feeding children in different age groups. Most urban caregivers had poor understanding on frequency of feeds than rural caregivers for ages 9-23 months. This indicates that knowledge flow to the community is more effective in rural than urban caregivers, but the exact source of knowledge in child nutrition was not investigated in this study. Since about half of the caregivers did not know the quantity of food for children in the different age groups this shows poor monitoring of a child's intake at caregiver level. This could be leading to underfeeding of children explaining why these children have stunting. This is important because children can only eat a particular amount of food relative to their age and stomach size, (WHO \& UNICEF, 2006). Furthermore inadequate quantity of food has been identified as one of the causes of malnutrition in Kenya, (Nutrition Division, 2013\&WHO, UNICEF, 2006).

Intake of varied foods ensures supply of different nutrients to a child. Caregivers were aware of the different food groupings a child should consume. Carbohydrate rich foods had the highest score while animal source was least mentioned with eggs scoring least. Although egg have been found to supply high quality protein as they contain high levels of essential amino acids, B vitamins, iron, selenium and zinc, it is fed less to children due to allergy concerns, (Shapira., 2009). Despite this concerns some studies have indicated early introduction of eggs in children 6-9 months in a randomized control trial showed no signs of instant allergic reaction and there was improved length in those who were given one egg per day compared to those who did not receive eggs, (Lora et al., 2017). The data on carbohydrates as the main type of foods that caregivers indicated should be fed to children and eggs as the least food to be fed, explains the findings in this study where children consumed more of carbohydrates and less of protein rich foods especially eggs. This gap in knowledge therefore seems to be influencing what children are fed on resulting to stunting as Negash et al., (2015) commented that lack of information on infant and young child nutrition was found to contribute to stunting in children.

\section{Limitation}

Interviewing all caregivers would have taken more days and resources and this was countered by getting a sample from, study population. Secondly since foods consumed in some homes are varied from season to season the responses given could reflect only what caregivers have in the data collecting period.

\section{Conclusion}

The findings on stunting in children less than two years indicate caregiver had a better understanding on feeding children less than six months on timely initiation of breastmilk and type of food. In addition, knowledge on meal was low suggesting no or poor monitoring of sufficient food intake by the caretakers. Animal source foods especially eggs scored least on types of foods to be fed to children.

\section{Recommendations}

The researcher suggests:

- $\quad$ Since most caregivers were children's biological mother's and were knowledgeable on feeding children below six months education sustaining breastfeeding can improve breastfeeding rates

- Health workers, community health volunteers, caregivers and should be educated on complimentary feeding of different age groups.

- Promotion of foods from all food groups should be done at community level and reasons for not feeding particular foods identified and addressed

\section{References}

i. Briend, A., Khara, T., \& Dolan, C. (2015). Wasting and stunting-similarities and differences: Policy and programmatic implications. Food and Nutrition Bulletin, 36(1), S15-S23. https://doi.org/10.1177/15648265150361S103

ii. Comprehensive Food Security and Vulnerability Analysis (CFSVA) Kenya 2016.

iii. Fairbrother, N., \& Stanger-ross, I. (2009). Reproductive-Aged Women ' s Knowledge and Attitudes Regarding Infant-Feeding Practices : An Experimental Evaluation, 6-8. https://doi.org/10.1177/0890334409352853

iv. Food Summit, FAO. (2009). Declaration of the World Summit on Food Security. World Food Summit, (November 2009), 16-18.

v. From Promise to Impact Ending Malnutrition by 2030 Summary. https://doi.org/10.2499/9780896299948

vi. Ghosh, S. (2016). Protein Quality in the First Thousand Days of Life. Food and Nutrition Bulletin, 37(Supplement 1), S14-S21. https://doi.org/10.1177/0379572116629259

vii. Global hunger index, (2015) 
viii. Herforth, A., \& Ahmed, S. (2015). The food environment, its effects on dietary consumption, and potential for measurement within agriculture-nutrition interventions. Food Security, 7(3), 505-520. https://doi.org/10.1007/s12571-015-0455-8

ix. International Food Policy Research Institute (IFPRI), (2016). Global Nutrition Report 2016 Kothari C.R.,' Research Methodolgy Methods \& Techniques' Second Edition, New Delhi: New Age International publisher, 2004

x. Kenya Demographic and Health Survey ( KDHS ) Millennium Development Goals for 2015. (2014).

xi. Leroy, J. L., Ruel, M., Frongillo, E. A., Harris, J., \& Ballard, T. J. (2015). Measuring the food access dimension of food security: A critical review and mapping of indicators. Food and Nutrition Bulletin, 36(2), 167-195. https://doi.org/10.1177/0379572115587274

xii. Lora, L. (2017). Eggs in Early Complementary Feeding and Child Growth : A Randomized Controlled Trial. https://doi.org/10.1542/peds.2016-3459

xiii. Maternal Infant and Young Child Nutrition (MIYCN) MoH Kenya Guidelines. (2012).

xiv. Negash, C., Whiting, S. J., Henry, C. J., Belachew, T., \& Hailemariam, T. G. (2015). Association between maternal and child nutritional status in Hula, rural Southern Ethiopia: A cross sectional study. PLoS ONE, 10(11), 1-8. https://doi.org/10.1371/journal.pone.0142301

xv. Njiru, J., \& Matiri, E. (2013). Maternal, Infant and Young child nutrition: National: National Operational Guidelines for health workers, 18-160.

xvi. Prendergast, A. J., Humphrey, J. H., Prendergast, A. J., \& Humphrey, J. H. (2017). Paediatrics and International Child Health The stunting syndrome in developing countries The stunting syndrome in developing countries, 9047(May). https://doi.org/10.1179/2046905514Y.0000000158

xvii. Shapira, N. (2009). Modified egg as a nutritional supplement during peak brain development: A new target for fortification. Nutrition and Health, 20(2), 107-118. https://doi.org/10.1177/026010600902000203

xviii. Sorgho, R., Franke, J., Simboro, S., Phalkey, R., \& Saeurborn, R. (2016). Nutrition and Climate ( NUTRICLIM ): Investigating the relationship between climate variables and childhood malnutrition through agriculture, an exploratory study in Burkina Faso. Public Health Reviews, 1-5. https://doi.org/10.1186/s40985-016-0031-6

xix. UNICEF_Expanded_Global_Databases_Stunting_April_2019.

xx. United Nations Children's Fund (UNICEF) World Health Organization, \& International Bank for Reconstruction and Development/The World Bank. (2018). Levels and trends in child malnutrition: key findings of the 2018 Edition of the Joint Child Malnutrition Estimates, 1-16. https://doi.org/10.1016/S0266-6138(96)90067-4

xxi. World Health Organization, \& UNICEF. (2006). Infant and young child feeding counselling: an integrated course. Who, 1-265. Retrieved from http://www.who.int/nutrition/publications/IYCF_Participants_Manual.pdf

xxii. Yaméogo, C. W., Cichon, B., Fabiansen, C., Rytter, M. J. H., Faurholt-Jepsen, D., Stark, K. D., Lauritzen, L. (2017). Correlates of whole-blood polyunsaturated fatty acids among young children with moderate acute malnutrition. Nutrition Journal, 16(1), 44. https://doi.org/10.1186/s12937-017-0264-3 